\title{
Anticancer Study of Wonogiri's Curcuma Xanthorhiza roxb Ethanol Fraction as Jamu by Flexible Docking Methods
}

\author{
T. Setiawan ${ }^{1 *}$, L. Ambarsari ${ }^{1}$ and T. Ibnu Sumaryada ${ }^{2}$ \\ ${ }^{1}$ Department of Biochemistry, Bogor Agricultural University, Indonesia \\ ${ }^{2}$ Department of Physics, Bogor Agricultural University, Indonesia \\ Itirtasetiawan@apps.ipb.ac.id
}

\begin{abstract}
Wonogiri's Curcuma Xanthorizha roxb in Indonesia is famously consumed as traditional drinking called as Jamu. It contains active phytochemical compounds called as curcuminoids in its ethanol fraction. Curcuminoids are natural derivative compounds comprised by three major substances, such as curcumins, demetoxycurcumins and bisdemetoxycurcumin. Those of reported to have anticancer activity. Most of the cancer cells show such a rapid duplication that surely fast in growing and proliferating, both characteristics are driven by enzymes called as Topoisomerase, more precisely, type II DNA topoisomerase. According to those of activity, curcuminoids are very potential to be investigated. Flexible docking methods, a kind of Bioinformatics study, is method that cheap, fast and easy enough to use. It has been widely used and strongly aimed to give prediction about such the potential compounds. Flexible docking between curcuminoids and active sites of type II DNA topoisomerase performed using Autodock vina reveals that curcuminoids have various interactions and bondings among active site areas Aspartic acid $^{479}$, Arginine $^{503}$, Glysine $^{478}$, Glutamine $^{778}$, Adenine $^{12}$, Guanine $^{13}$, Timine ${ }^{9}$, Cytosine $^{8}$ and Metionine ${ }^{782}$. Exposure of Gibbs free energy to curcuminoids docking study show the structure-dependent increase in binding value compared to standard etoposide. Gibbs free energy of curcumin is $-9.2 \mathrm{kcalmol}^{-1}$ noted as the highest followed by -8.6 kcalmol ${ }^{-1}$ of demetoxycurcumin and $-8.2 \mathrm{kcalmol}^{-1}$ of bisdemetoxycurcumin for the second and third respectively. ADME/Tox assessment performed using ACDLab software results that curcumin shows a number of problems in its bioavailability however curcuminoids are relatively safe to consume generally. These data suggest that curcuminoids predicted to have potential as anticancer activity. Furthermore, Wonogiri's curcuminoids contained in Jamu as traditional drinking formulas predicted safe to consume bioinformatically.
\end{abstract}

Keywords: Bioinformatics, curcuminoids, flexible docking, Gibbs free energy, type II DNA topoisomerase

\section{Introduction}

Jamu is traditional drinking originated from java, Indonesia. Indonesian people commonly made of Jamu by series of mixed plants and Curcuma Xanthorhiza roxb is the most critical. In Indonesia is Temulawak another name of Curcuma Xanthorriza roxb. Most Indonesian people believe that Jamu could cure all of the diseases, simply mean, if their relation immediately get a sick, the first treatment drinks a glass of Jamu even they do not precisely know what kind of that diseases. It is so massively to do in Indonesia.

Recent studies have demonstrated that Curcuma Xanthorhiza roxb majority made of three active compounds, these are curcumin, demetoxycurcumin and bisdemetoxycurcumin together they called by curcuminoids [1-2]. The percentage of curcuminoids might be different from one place to another. It depends on climates and 
soil nutrient differences. Wonogiri's Curcuma Xanthorriza roxb has been discovered to have the highest percentage of containing curcuminoids compared among Ciemas's, Sukabumi's and Balitro's Curcuma Xanthorhiza roxb [3]. The anti-inflamation potential of curcuminoids has been studied extensively [4]. Moreover, curcuminoids has been recently studied to investigate its function to cure a wide range of diseases in Indonesia [5]. The highlight study of curcumin not curcuminoids against cancer diseases has been successfully done. However, the study of curcuminoids, curcumins and its natural derivative, against cancers is very rare to be found whereas it could explain the role of curable diseases by Jamu.

Cancer noted as the first disease cause the highest mortality rate in decade. Cancer is marked with immortal properties and rapid enough of duplication. Every cell can reach very abundant immediately, it just a second. That malignant function is driven by special enzyme named as type II topoisomerase which its function is to reveal front-end the tangled DNA lest the replication process could be started [6-7]. Most of cancer cells demonstrated abnormality to that of enzyme, it has high level synthesis. Consequently, the level of replication would increase and unstoppable [8]. Inhibiting that enzyme will down regulate the level of replication and cure the cancers. By using Bioinformatics methods, the additional data could be collected computationally. Flexible docking performed by Autodock vina aimed to collect predictions of potential interactions binding types and Gibbs free energy to explain how strong the affinity between curcuminoids to that enzyme are [9]. ADMETox performed by ADBlab aimed to assess and predict how safe they are [10].

\section{Experimental Details}

AutoDock Vina, including user interface named, Autodock Tool (ADT), was used for docking simulation. The ADT was used for preparing between ligand and receptor by PDBQT extension convertor. Not only act as convertor but also it can facilitate AutoGrid to make grid for suitable docking area.

\subsection{Receptor Preparation}

The three dimensional structure of Protein chosen as target identification is type II DNA topoisomerase PDB: 3QX3 [11] collected from Protein Data Bank (PDB) [12]. That of ternary complex system, by using ADT software, the inhibitor Etoposide, cofactor $\mathrm{Mg}$ and all water molecules were removed, leaving only the residue of receptor. Preparations were involved the addition of polar hydrogen, correcting the calculation of partial charge and Gasteiger charges were calculated for each atom. The three dimensional structure of protein 3QX3 was shown in Figure 1 (dsDNA colored by green, Toprim and 5Y-CAP subdomain colored by orange and cyan respectively).
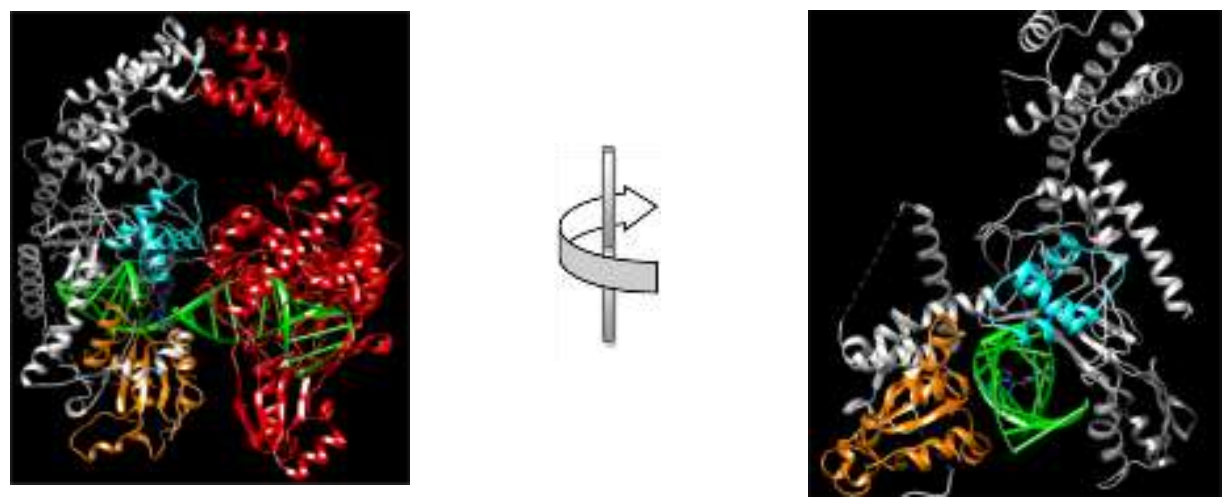

Figure 1. Three Dimensional Structure of Protein [PDB: 3QX3] 


\subsection{Ligand Preparation}

Curcuminoids compounds, curcumin, demetoxycurcumin and bisdemetoxycurcumin were synthesized by MarvinSkecth software and were minimized by AM1 force field. They are used as ligand. The structure ligand was shown in Figure 2. By using ADT, ligands were calculated for torsion. It is the most method to allow the ligands free titling to suitable fit on surface of receptors during the searching algorithms and scoring functions.

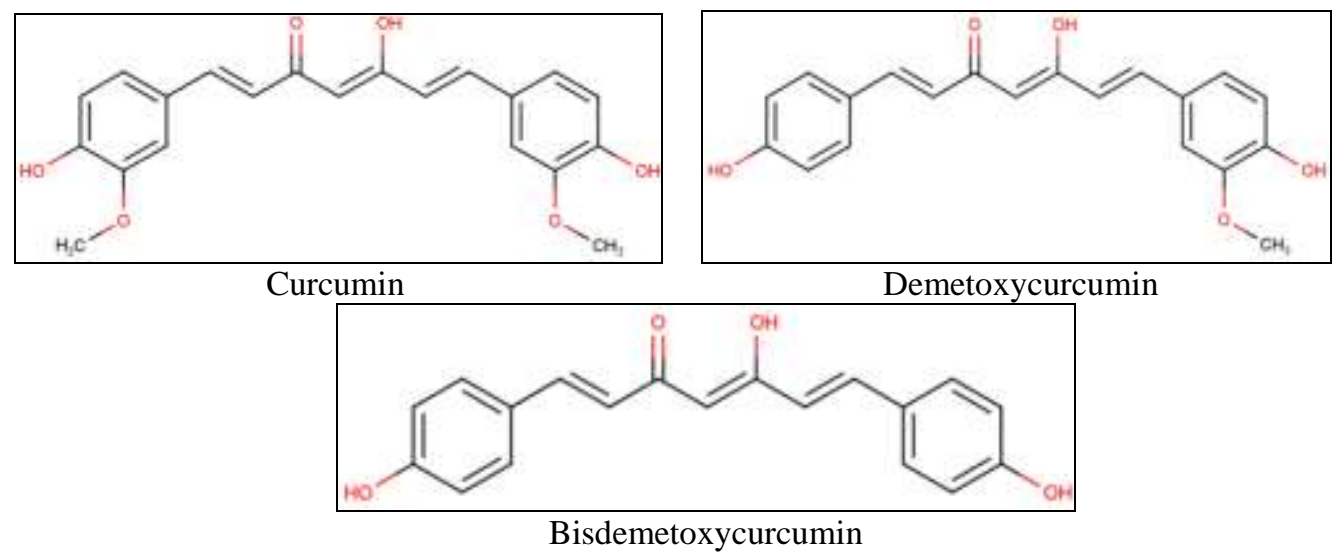

Figure 2. Curcuminoids Ligands

\subsection{Comparative Ligand Preparation}

Type II DNA topoisomerase inhibitor such as Etoposide were included in the docking analysis as comparative studies. Etoposide was retrieved from NCBI pubchem compound database [13]. The downloaded structure was in SDF extension. PDB extension is should be used so, OPEN BABEL software was performed to convert it to PDB [14]. The structure of this drug was shown in Figure 3. This comparative ligand, Etoposide, was calculated its torsion performed by ADT.

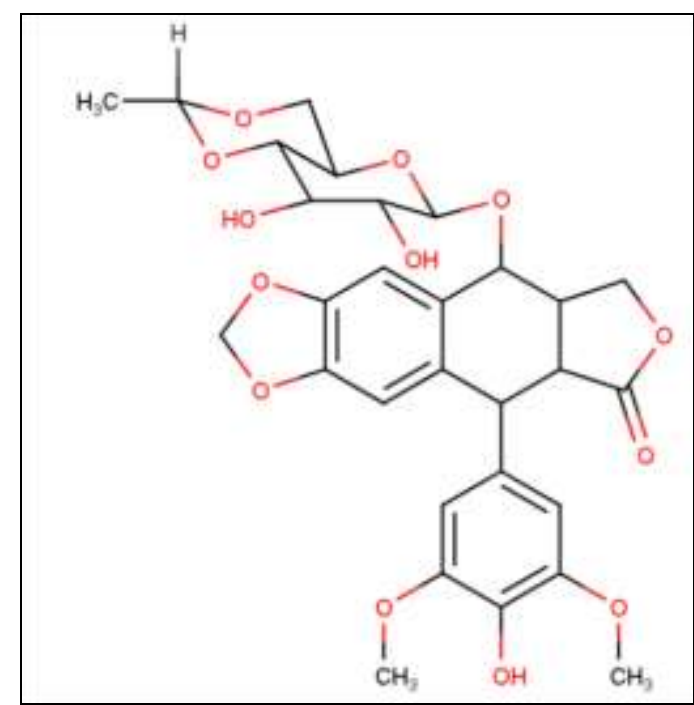

Figure 3. Comparative Ligand (Etoposide) 


\subsection{Lipinski's Rule}

Lipinski's rules were determined by online tools at http://www.scfbio-iitd.res.in. Lipinski's rule state, that most drug-like molecules have $\log \mathrm{P} \leq 5$, molecular weight $\leq$ 500 , number of hydrogen bond acceptor $\leq 10$ and donor $\leq 5$ [15].

\subsection{Validation of Docking Parameter}

As a test for confirming the docking algorithm ability to reproduce the co-crystallized pose of inhibitor is valid. The three dimensional structure of protein coded by $3 \mathrm{QX} 3$ were include its inhibitor and other ligands such as water molecule, ions and metals in that of characterization process. To benchmarking methods, all ligands had already been removed then; Native inhibitor was redocked to the original site, where it has been removed. The docking validation was done in 10 times of set, every set was identified the lowest RMSD value, it demonstrated the capability of AutoDock in reproducing the best experimental result.

\subsection{Flexible Docking using AutoDock Vina}

The docking area was visually attempted in area that presumed as the active site. A grid of $80 \AA$ x $80 \AA$ x $80 \AA$ with grid spacing of 0.375 was positioned around the active site with all the ligand atom types using AutoGrid. An electrostatic map was also calculated. In addition, to undergo the flexible docking method, some ligands around the active sited presumed as important amino acids were noted and were assigned into special saving form, for instance adding flexible docking of saved name, to distinguish between rigid and flexible during docking calculation. Exhaustiveness number was assigned up to 250 for docking calculations [16].

\subsection{ADME/Tox Measurement}

ADME/Tox (Adsorption, Distribution, Metabolism, Excretion and Toxicity) was performed by using ACDLab online by access in https://ilab.acdlabs.com/iLab2 [17].

\section{Theoretical Aspects}

Docking Study is an effective study to predict of intermolecular interaction of one particular compound. In docking there are some term commonly used, such as 'ligand' it is the technical term to call a small molecule that will be docked to specific site of the protein and 'receptor' is that the specific site of the protein that will be targeted to be observed. It could be either proteins or DNA, or among domain, sub-domain or even novel part that has critical role for that enzyme activity.

Simulating interaction between two molecules is a multiple problem because there are many force involved in that of system, including van der waals, hydrophobic, or stacking contact among aromatic amino acids, hydrogen bonding and electrostatic forces. Generating and modelling interactions intermoleculary in ligand-protein complex is tricky whereas there are so many freedom degrees and also limited knowledge of solventdependent effect on the binding groups. Ligand docked to binding site tries to mimic the natural environment of interaction between ligand and its receptor via Gibbs free energy (the lowest energy) [18]. Docking protocols is described as combinations between search algorithm, and scoring functions.

\subsection{The Search Algorithm}

Docking processes between protein and ligand at an advance level is head of conformational problem such as how flexible between protein and ligand is allowed. There are have some searching algorithms include molecular dynamics, Monte Carlo 
methods, genetic algorithms, fragment-based, point complementary and distance geometry methods, Tabu, and systematic searches. Searching algorithm is supposed to

\subsection{Scoring Function}

The scoring function calculates a numerical score for a conformation based on its coordinates and mostly, in a high-throughput screening, a scoring function must be simple enough to calculate a thousand of times protein-ligand docking. The three important applications of scoring functions in molecular docking are; the firstly is to determine the binding mode and site of a ligand on protein, the second is to predict the binding affinity between protein and ligand and the last is to identify the potential drug hit to the protein or that of hit for given target of protein by searching a large number of ligand database.

\subsection{Rigid-Body Methods Types}

Protein-ligand docking may be classed into three classes based on how much the rearrangement that they allow the protein and ligand to undergo.

- $\quad$ Rigid docking, the docking process of the ligand to the protein while the protein receptor is in fixed conformation. Receptor conformations is experimentally determined by X-ray crystallography combined with nuclear magnetic resonance structures. Rigid methods are still common in protein-protein docking, instead of protein-ligand docking.

Semi-flexible, or flexible-ligand docking, in this method, the ligand is freely allowed to change its conformations and the receptor of proteins is held in rigid state. These methods are the most commonly used in docking method. In natural biological system it seems like to lock and key.

- $\quad$ Flexible receptor docking, interestingly these methods is similar to others docking methods, the ligand is still allowed to freely change its conformational change. Indeed, the receptor is just allowed limited flexibility while full flexibility of the protein is commonly an intractable problem. In natural biological system it seems like to induce-fit [19].

\section{Results and Discussions}

\subsection{Identification of Receptor}

Type II DNA topoisomerase [PDB: 3QX3] is the critical enzyme that its role is to initiate the DNA replication in S0 phase. Its function is facilitated by special intermolecular sub-domain called TOPRIM and 5Y-CAP sub-domain in the central terminal whereas the most important activity of that enzyme held at there, such as cleavage, through it cross and rejoining DNA.

The geometrical stability could be evaluated by using Ramachandran's plot computed facilitated in PDB bank. This result revealed $99.9 \%$ of the residues that were in the favorable regions, $98 \%$ in generously allowed regions and less than $1 \%$ in disallowed regions. Accordingly, the three dimensional structure of protein $3 \mathrm{QX} 3$ is considered as stable regarding in its geometry, moreover it has $2.16 \AA$ of resolution so it had high resolution of quality [20]. The Ramachandran's plot of three dimensional structure of 3QX3 was shown in Figure 3. 


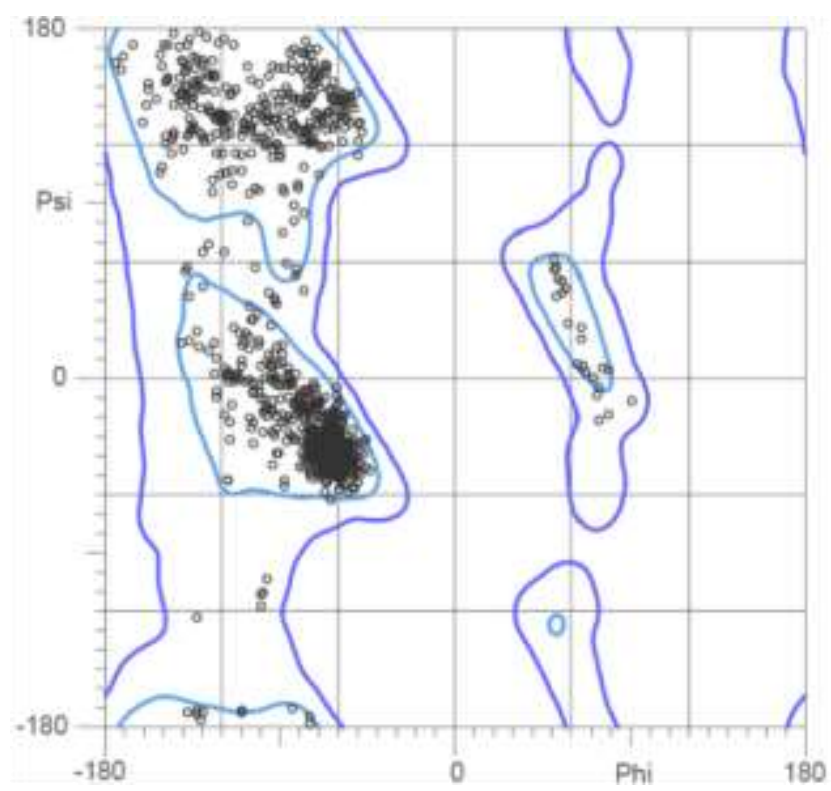

Figure 4. Ramachandran's Plot of $3 Q \times 3$

Receptor used in the flexible docking was determined by side-chain flexibility. Amino acids in the areas $3 \AA$ around active site were noted as residues considered as well allowed to freely fit on ligand surface to make better position bonding [21]. The receptor binding of ligand was show in Figure 5. There are two important amino acids from TOPRIM sub-domain (orange), they are $\mathrm{Arg}^{503}$ and $\mathrm{Asp}^{479}$ and also three important amino acids form 5Y-CAP (cyan) sub-domain, they are $\mathrm{Gln}^{778}$, $\mathrm{Met}^{782}$ and Pro $^{819}$. Base on receptor Figured 5, between the double strands DNA (green), base Cytosine $\left(\mathrm{DC}^{8}\right)$ and base Tymine $\left(\mathrm{DT}^{9}\right)$ have one nick, this nick provides enzyme to repair topography of DNA then facilitates other transcription enzymes, such as DNA polymerases, primase or telomerase, start to replicate its host cell (cancer cells) [22].

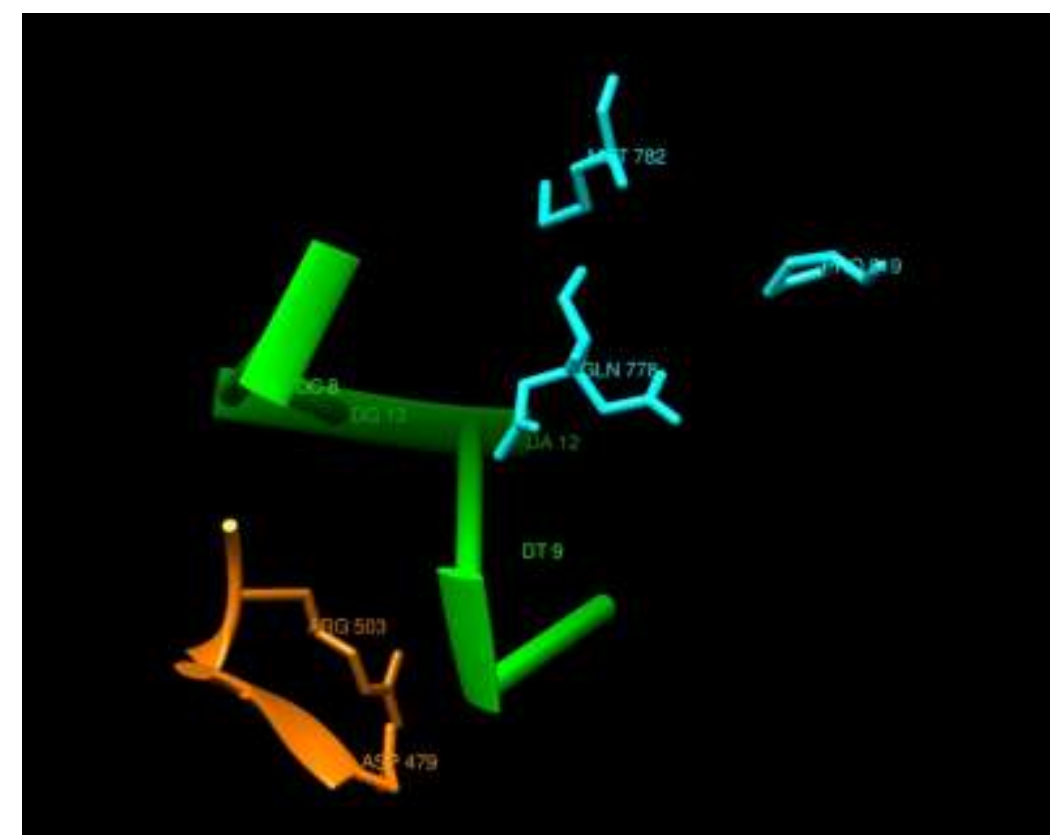

Figure 5. Receptor 


\subsection{Ligand Identifications}

All ligands used in docking were identified to have a requirement docking capability. All ligand should pass the Lipinski's rule [23]. The docking simulation were predicted occurred in intercellular level, so it means that before the interaction between ligand and receptor happen, the ligand must be capable to pass the body's barrier such as bioavailability, lipid bilayer, and enzyme degradation. In this case Lipinski's rule were commonly used to filter and to assess the ligand by using the rule called the rule of five. The ligand that have not pass the Lipinski's rule is recommended to use by injection. The result of filtering ligands by Lipinski's rules was shown in Table 1.

Tabel 1. Filter Lipinski

\begin{tabular}{|c|c|c|c|c|}
\hline $\begin{array}{l}\text { Lipinski's } \\
\text { rule }\end{array}$ & Etoposide* & Curcumin & $\begin{array}{l}\text { Demetoxy } \\
\text { curcumin }\end{array}$ & $\begin{array}{l}\text { Bisdemetoxy } \\
\text { curcumin }\end{array}$ \\
\hline $\mathbf{A}$ & 588 & 368 & 338 & 308 \\
\hline B & 1.1059 & 2.823 & 2.811 & 2.799 \\
\hline C & 3 & 3 & 3 & 3 \\
\hline D & 13 & 3 & 2 & 1 \\
\hline $\mathbf{E}$ & 137.41 & 102.965 & 96.413 & 89.861 \\
\hline \multicolumn{5}{|l|}{ keynoted: } \\
\hline \multicolumn{5}{|c|}{ * $\quad$ : Comparative ligand } \\
\hline \multicolumn{5}{|c|}{$\mathrm{A} \quad: \mathrm{Mr}<500$} \\
\hline \multicolumn{5}{|c|}{$\mathrm{B} \quad: \log \mathrm{P}<5$} \\
\hline \multicolumn{5}{|c|}{ C $\quad$ : Hydrogen donor $<5$} \\
\hline \multicolumn{5}{|c|}{$:$ Hydrogen acceptor $<10$} \\
\hline \multicolumn{5}{|c|}{ E : Molar refraktifity $40-130$} \\
\hline
\end{tabular}

All curcuminoid ligands look met a requirement the Lipinski's rule. It means that all curcuminoid ligands can pass the body's barrier to interact with receptor of enzyme. Consequently, those of considering being able to use the docking.

\subsection{Validation of Searching Algorithm and Scoring Function}

Native ligand in ternary complex PDB 3qx3 was used to validate docking algorithm and scoring function used in flexible docking. Exhaustiveness value of 250 was performed to give high precision option in docking study. Size of grid box set in $80 \mathrm{x} 80 \mathrm{x}$ 80 and center set to center by ligand were result a very less RMSD value, $0.06 \AA$. RMSD that less than $2.0 \AA$ indicated the method used for searching algorithm and scoring function was valid [24]. The validation of result of conformation and binding mode were shown in Figure 6.

Ligand within yellow color indicated the original site and conformation before validation and that of soft blue color indicated the site and conformation after performed validation. They are looks overlapping one another were reflected by its very less RMSD value. Based on Figure 6 and flexible docking method, residue $\mathrm{Arg}^{503}$ and $\mathrm{Asp}^{479}$ demonstrated the most flexible residue, their side chain went down slightly than those of before. Moreover, so many was hydrogen bonding happen around the ligand and $\mathrm{Asp}^{479}$ was considered as the most important residue to that of binding because three hydrogen bonding occurred on it. Amino acid $\mathrm{Gln}^{778}$ and base cytosine $\left(\mathrm{DC}^{8}\right)$ also show one hydrogen bonding.

Binding mode of comparative ligand show intercalate binding mode, demonstrated by it taking places in nick position, between base cytosine $\left(\mathrm{DC}^{8}\right)$ and base tymine $\left(\mathrm{DT}^{9}\right)$. Intercalate mode is believed to give extraordinary effect in dsDNA problem lead to apoptotic pathway. 


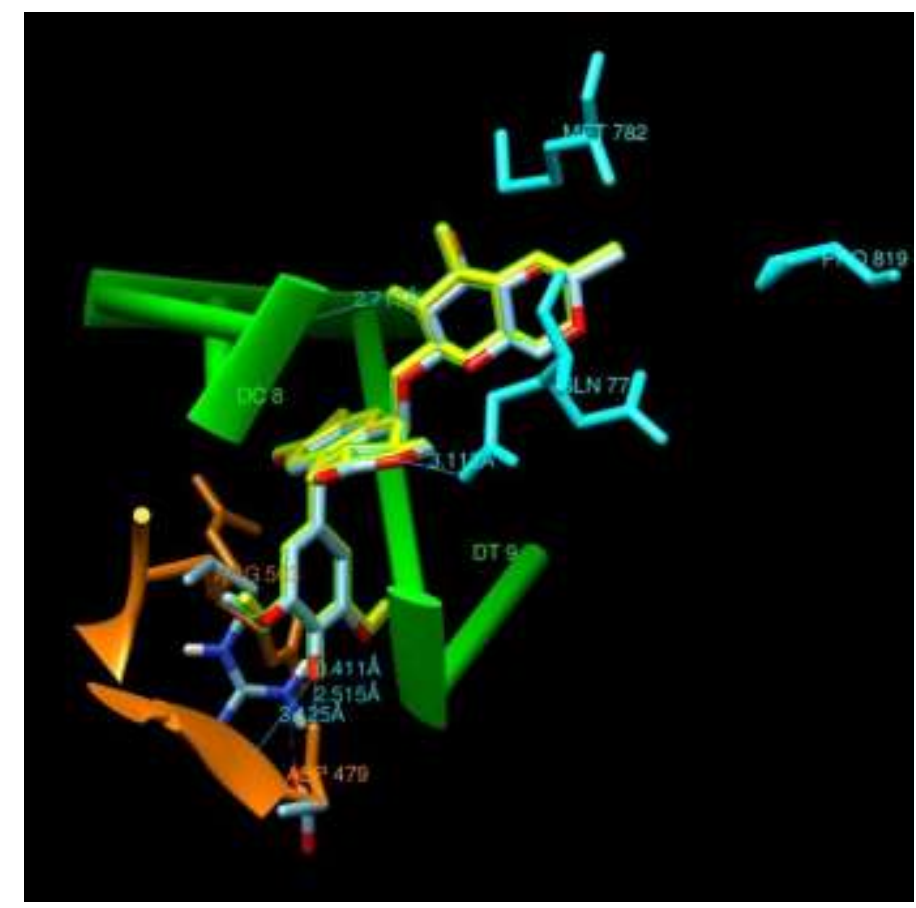

Figure 6. Validation of Conformational Interaction Results

\subsection{Bonding Affinity}

Analysis of ligand curcuminoids binding interaction with type II DNA topoisomerase can be very useful for new preventive and therapeutic drug for cancer, especially for herbal formulation such as Jamu. Flexible docking simulation of all ligands into type II DNA topoisomerase enzyme produced negative Gibbs free energy, it indicates curcuminoids have high affinity to that of enzyme similar to comparative ligand etoposide [24]. Although, comparative ligand affinity is still higher than is curcuminoid affinity. Gibbs free energy among ligand etoposide, curcumin, demestoxycurcumin and bisdemestoxycurcumin found to be $-13.9 \mathrm{kcalmol}^{-1},-9.2 \mathrm{kcalmol}^{-1},-8.6 \mathrm{kcalmol}^{-1}$ and -8.2 $\mathrm{kcalmol}^{-1}$ respectively (shown in Figure 7).

The result obtained from this study would be useful in both understanding the inhibitory mode as well as rapidly and accurately predicting the activities of new inhibitors on the basis of docking scores.

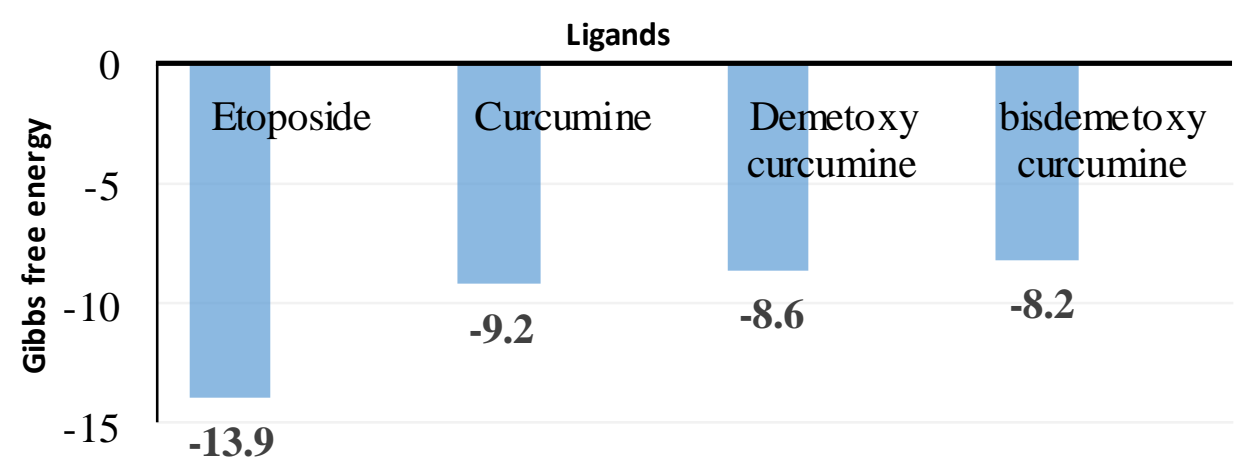

Figure 7. Gibbs Free Energy of Ligands 
Among the curcuminoids member, curcumin has the highest affinity followed by demetoxycurcumin and bisdemetoxycurcumin. All member curcuminoids shown to have potency as type II DNA topoisomerase inhibitor.

\subsection{Binding Modes and Interactions}

The aim of ligand-protein docking is to predict the predominant binding model of ligand with a protein of known three dimensional structure. The detection of ligandbinding sites is commonly the starting point for protein function identification and drug discovery [25]. Intermolecular flexible docking simulations were performed and the docked conformation of type II DNA topoisomerase complex. This study yielded critical information regarding the orientation of inhibitor in binding pocket of target protein considering that the intercalation binding mode was an important to study. The ligand binding modes and interactions for comparative ligand, curcumin, demetoxycurcumin and bisdemetoxycurcumin were demonstrated in Figure 7 to 10 respectively.

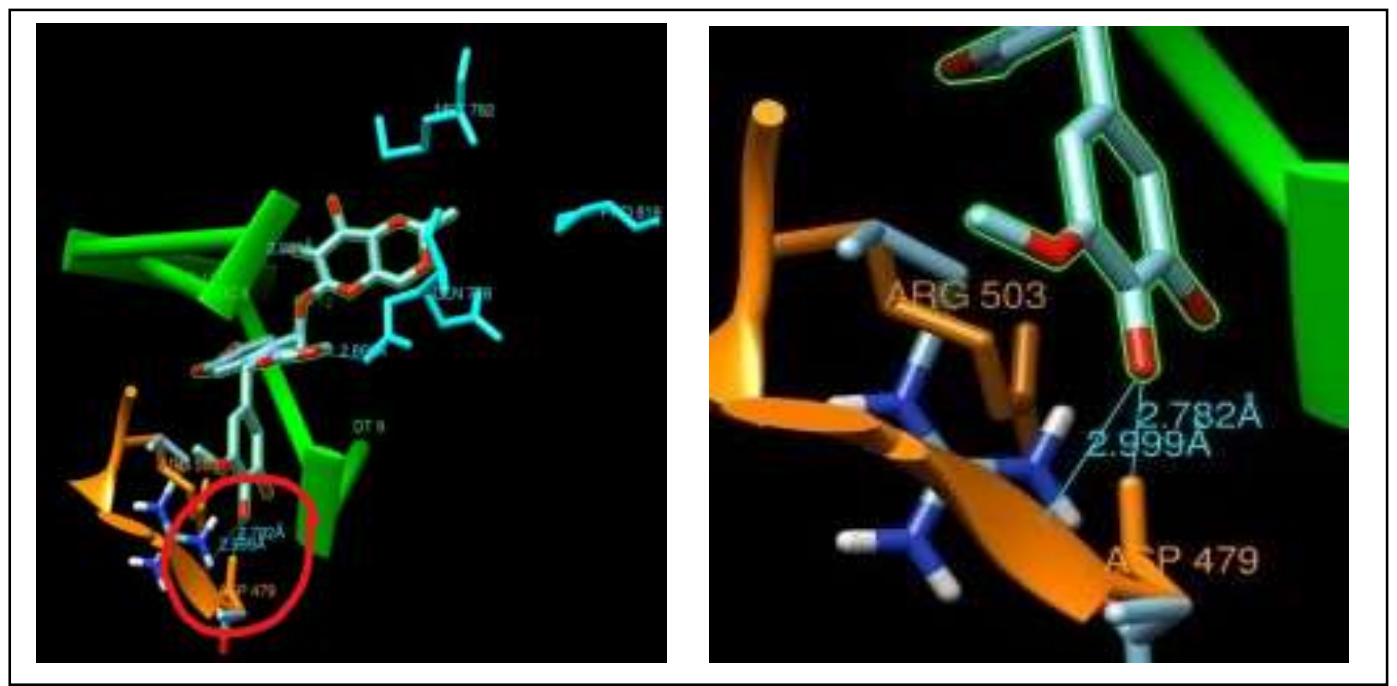

Figure 7. Comparative Ligand Binding Interaction

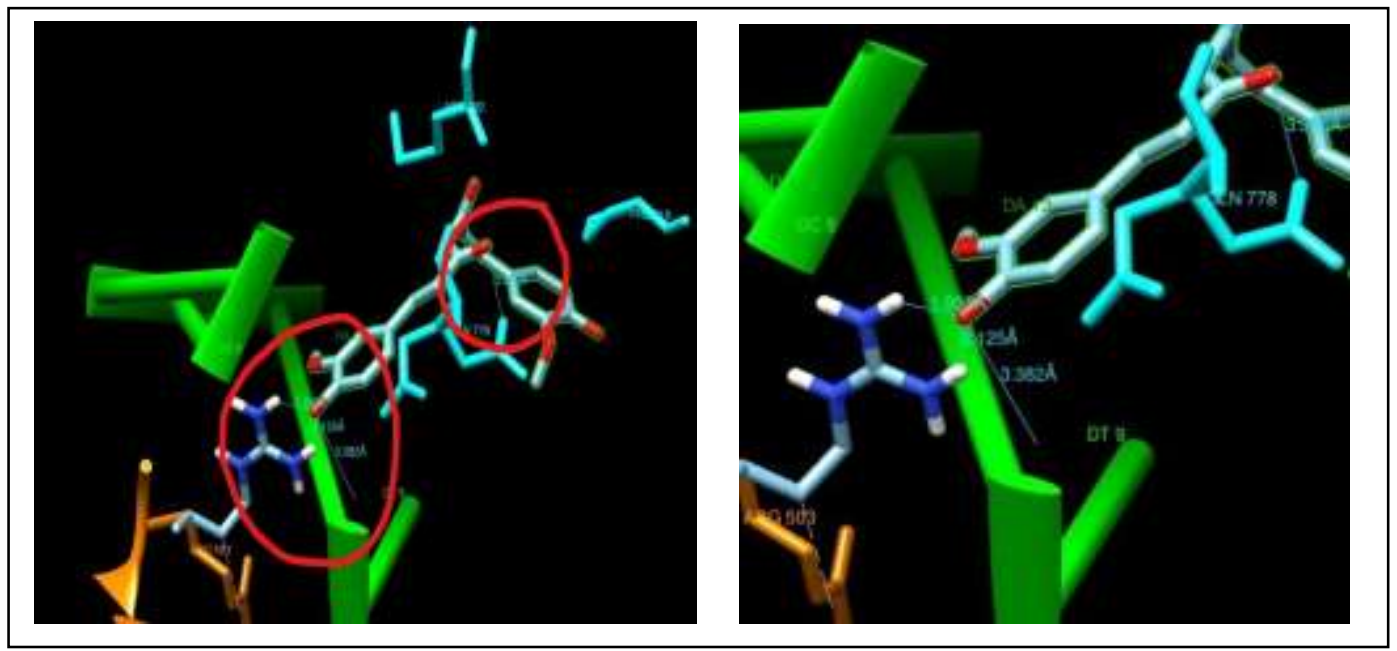

Figure 8. Curcumin Binding Mode and Interaction 


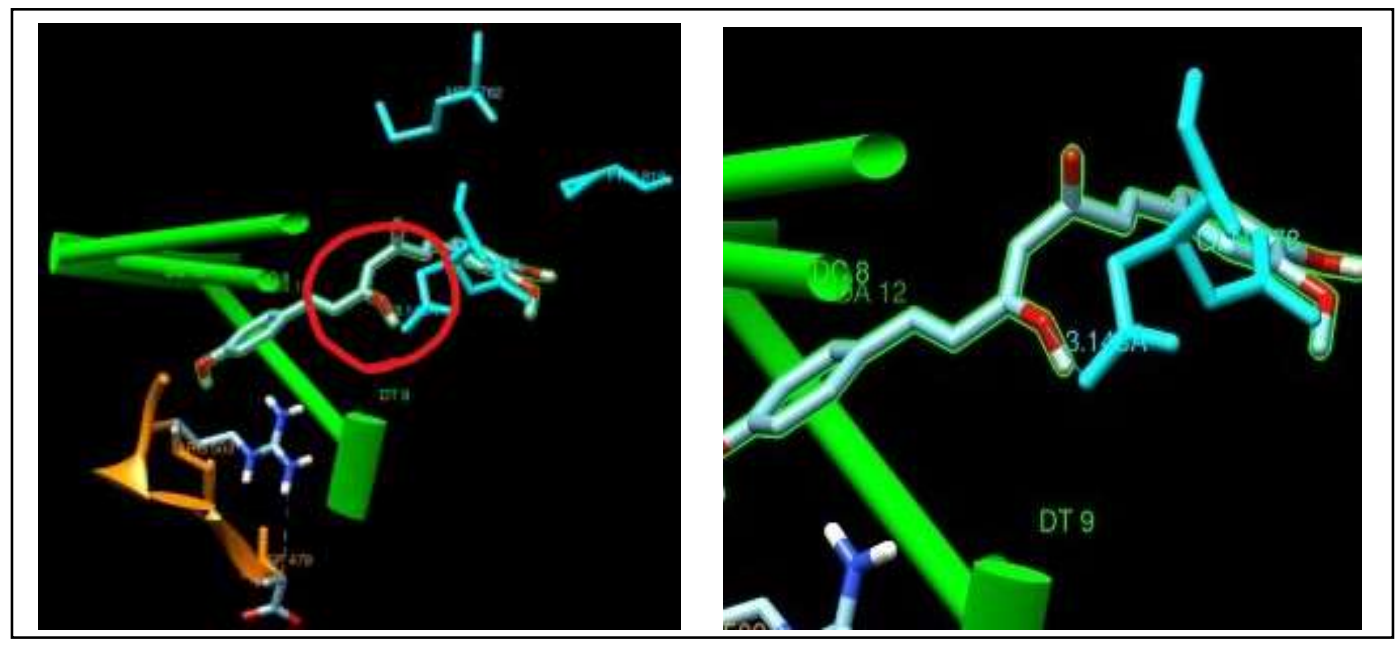

Figure 10. Bisdemetoxycurcumin Binding Mode and Interaction

The majority of the curcuminoid ligands had a greater binding affinity to the same pocket with comparative ligand, moreover binding mode also shown similar to comparative ligand. This binding mode was called by intercalated binding mode, a small molecule which posed crossly between two nicked dsDNA. Furthermore, curcuminoids would be predicted as potential drug grouped in type of drug which has intercalated action. All member of curcuminoids also shown the interaction to residues $\mathrm{Arg}^{503}, \mathrm{Asp}^{479}, \mathrm{Gln}^{778}$, $\mathrm{Met}^{782}$ and $\mathrm{Pro}^{819}$. Residues $\mathrm{Arg}^{503}$ and $\mathrm{Asp}^{479}$ from TOPRIM sub-domain were shown to have the most fluctuation in action, it indicated that both residues were the most flexible residues. Because the residue $\mathrm{Asp}^{479}$ shown the major responsible to form hydrogen bonding on all curcuminoids except bisdemetoxycurcumin it predicted as an important residue that held the curcuminoids to stay in pocket in suitable mode (intercalation mode). Residue $\mathrm{Gln}^{778}$ from 5Y-CAP sub-domain shown an important role to held curcuminoids to stay in its mode by hydrogen bond on it except bisdemetoxycurcumin. Bisdemetoxycurcumin show no hydrogen bond on it but it has intercalation binding mode by other interactions form residues around it. Generally, all member of curcuminoid ligands could be able to inhibit activation on type II DNA topoisomerase by intercalation mode to stop replication and to promote in apoptotic pathway.

\subsection{Toxicity and Safety Properties}

QSAR techniques are widely used in lead optimization-like processes. QSAR study were performed ADME/Tox filtering server from ADMElab to determine of the molecular inhibitory properties such as the oral bioavailability, passive adsorption and health effect [26]. Calculated molecular properties of toxicity of all ligands were shown in Table 2.

Table 2. Molecular Toxicity

\begin{tabular}{|c|l|c|c|c|c|c|c|}
\hline \multirow{2}{*}{$\begin{array}{c}\mathbf{N} \\
\mathbf{0}\end{array}$} & \multirow{2}{*}{\begin{tabular}{c} 
Ligands \\
Oroavailabilit \\
\cline { 4 - 8 }
\end{tabular}} & $\begin{array}{c}\boldsymbol{y} \\
\mathbf{1}\end{array}$ & $\begin{array}{c}\text { Cardiovascular } \\
\text { system }\end{array}$ & $\begin{array}{c}\text { Gastrointestinal } \\
\text { system }\end{array}$ & Kidney & Liver & Lungs \\
\hline $\mathbf{2}$ & Curcumin & $30-70 \%$ & 1 & 0.97 & 0.59 & 0.78 & 0.79 \\
\hline $\mathbf{3}$ & $\begin{array}{l}\text { Demetoxy } \\
\text { curcumin }\end{array}$ & $30-70 \%$ & 0.85 & 0.02 & 0.26 & 0.7 & 0.33 \\
\hline $\mathbf{4}$ & $\begin{array}{l}\text { Bisdemeto } \\
\text { xy } \\
\text { curcumin }\end{array}$ & $>70 \%$ & 0.76 & 0.17 & 0.43 & 0.4 & 0.37 \\
\hline
\end{tabular}


* comparative ligands

The value of properties was explained by ratio 0 to 1 , the highest value the highest level of toxicity was gained but the commercial oral drugs has 0 to 5 value toxicity except $0-7$ value of cardiovascular system. Etoposide is the highest yield of commercial chemotherapeutic drug commonly used for injection not for oral so the molecular toxicity measurement would be shown to have a problem in health effect. In the other hand, curcuminoids relatively safe in health effect such as cardiovascular, kidney, liver, lungs and gastrointestinal systems compared by comparative ligand. The bioavailability curcuminoids also shown better than that ligand. Generally, among the curcuminoids, bisdemetoxycurcumin is the ligand that have the lowest toxicity level than those of ligand.

\section{Conclusion}

Curcuminoid ligands pose in the same site of type II DNA topoisomerase. Curcumin and demetoxycurcumin interact with type II DNA topoisomerase at $\mathrm{Asp}^{479}$ and $\mathrm{Gln}^{778}$ by hydrogen bonding, bisdemetoxycurcumin is not shown hydrogen bonding. These sited could be the best possible binding sited to inhibit the type II DNA topoisomerase with Gibbs free energy $-13.9 \mathrm{kcalmol}^{-1},-9.2 \mathrm{kcalmol}^{-1}$, -8.6 $\mathrm{kcalmol}^{-1}$ and $-8.2 \mathrm{kcalmol}^{-1}$ of curcumin, demetoxycurcumin and bisdemetoxycurcumin respectively. ADMETox measurement suggest that curcuminoids relatively safe in human metabolism. Ultimately, comparative flexible docking analysis also suggest that Wonogiri's curcuminoids in jamu formulation could act together as inhibitor type II DNA topoisomerase, an alternative source for cancer disease bioinformatically.

\section{Acknowledgments}

We would like to say thank to Directorate General of Higher Education of Republic Indonesia (DIKTI) for funding this research as "Postgraduate Educational Scholarships".

\section{References}

[1] P. Anand, S. G Thomas, A. B Kunnumakkara, C. Sundaram and K. B Harikumar, "Biological activities of curcumin and its analogues (congeners) made by man and mother nature", J. Biochem Pharm, vol. 76, (2008), pp. 1590-1611.

[2] A. Kumar and U. Bora, "In silico inhibition studies of NF-kB p50 sub unit by curcumin and its natural derivative", Med Chem Res. DOI: 10.1007/s004-011-9873-0, (2011).

[3] G. Permasku, "Aktivitas eskstrak kurkuminoid rimpang temulawak (Curcuma Xanthorrhiza roxb)dari berbagai aksesi terhadap inhibisi enzim alfa glukosidase secara in vitro", Bogor Agricultural University, Bogor, (2014).

[4] P. Maulina, "Aktifitas antiinflamasi sediaan nanopartikel ekstrak kurkumin temulawak tersalut asam palmitat secara invivo", Bogor Agricultural University, Bogor, (2014).

[5] B. B. Aggarwal, I. D. Bhatt, H. Ichikawa, K. S. Ahn, G. Sethi, S. K. Sandur, C. Natarajan, N. Seeram and S. Shishodia, "Turmeric: The Genus Curcuma", Taylor and Francis, New York, (2006), pp 298303.

[6] J. C. Wang, "cellular roles of DNA topoisomerases: A molecular perspective", Nat Rev Mol Cell Bio, vol. 3 , (2002), pp. 430-440.

[7] J. L. Nitiss, "Investigating the biological functions of DNA topoisomerases in eukaryotic cells", BBAGene Struct Expr, Vol. 1400, (1998), pp. 63-81.

[8] H. S. Abu and M. Zihlif, "Gene expression alteration in doxorubicin resistan MCF-7 breast cancer All Ine", Genomic, Vol. 101 (2012), pp. 213-220.

[9] A. D. Baxevanis and B. F. Ouellette, "Bioinformatics a Practical Guide to the Analysis of Genes and Proteins Second Edition”, (2001), pp. 1-457.

[10] R. Benigni, C. Bossa and O. Tcheremenskaia, "Nongenotoxic carcinogenicity of chemicals: mechanisms of action and early recognition through a new set of structural alerts", Chemical Reviews., vol. 5, no. 113, (2013), pp. 2940-57.

[11] C. C. Wu, T. K. Li, L. Farh, L. Y. Lin, T. S. Lin, Y. J. Yu, T. J. Yen, C. W. Chiang and N. L. Chan, "Structural basis of type II topoisomerase inhibition by the anticancer drug etoposide", Science, no. 333, (2011), pp. 459-462. 
[12] H. M. Berman, J. Westbrook, Z. Feng, G. Gilliland, T. N. Bhat, H. Weissig, I. N. Shindyalov and P. E. Bourne, "The Protein Data Bank Nucleic Acids Research", vol. 1, no.28, (2000), pp. 235-242.

[13] E. E. Bolton, Y. Wang, P. A. Thiessen and S. H. Bryant, "PubChem: integrated platform of small moleculesand biological activities", Annu. Rep. Comput. Chem., vol. 4, no. 12, (2008), pp. 217-241.

[14] J. Werner, Geldenhuys, E. Kevin, Gaasch, Mark, Watson, D. A. David and J. V. Cornelis, "Optimizing the use of opensource software applications in drug discovery", Drug Discovery Today, vol. 11, no.3-4, (2006), pp. 127-132.

[15] C. A. Lipinski, F. Lombardo, B. W. Dominy and P. J. Feeney, "Experimental and computational approaches to estimate solubility and permeability in drug discovery and development settings", Adv Drug Del Rev, vol. 1-3, no. 23, (1997), pp. 3-25.

[16] G. M. Morris, R. Huey, W. Lindstrom, M. F. Sanner, R. K. Belew, D. S. Goodsell and A. J. Olson, "AutoDock4 and AutoDockTools4: Automated docking with selective receptor flexibility", Journal of Computational Chemistry, vol. 16, (2009), pp. 2785.

[17] ACD/Structure Elucidator, version 15.01, Advanced Chemistry Development, Inc., Toronto, ON, Canada, www.acdlabs.com, (2015).

[18] S. F. Sousa, P. A. Fernandes and M. J. Ramos, "Protein-ligand docking: current status and future challenges. Proteins", vol. 1, no. 65, (2006), pp. 15-26.

[19] I. Halperin, B. Ma, H. Wolfson and R. Nussinov, "Principles of docking: an overview of search algorithms and a guide to scoring functions", Proteins, vol.4, no. 47, (2012), pp. 409-443.

[20] K. H. Bosco and R. Brasseur, "The Ramachandran plots of glycine and pre-proline", BMC Struc Bio, vol. 1-14, no. 5, (2005).

[21] H. M. Lu, D. C. Yin, Y. J. Ye, H. M. Luo, L. Q. Geng, H. S. Li, W. H. Guo and P. Shang, "Correlation between protein sequence similarity and x-ray diffraction quality in the protein data bank", Prot Pept Lett., vol. 1, no.16, (2009), pp. 50-5.

[22] J. C. Wang, "Cellular roles of DNA topoisomerases: A molecular perspective", Nat Rev Mol Cell Bio., vol. 3 (2002), pp. 430-440.

[23] C. A. Lipinski, F. Lombardo, W. D. Beryl and J. F. Paul JF, "Experimental and computational approaches to estimate solubility and permeability in drug discovery and development settings", Advanced Drug Delivery, vol. 46, (2001), pp. 3-26.

[24] [24] D. Nelson and M. Cox, "Principle of Biochemistry (5th Edn.)", W.H. freeman and company (USA), (2008), ISBN-13: 978-0-7176-7108-1.

[25] V. Srivastava, S. P. Gupta, M. I. Siddiqi and B. N. Mishra, "Molecular docking studies on quinazoline antifolate derivatives as human thymidylate synthase inhibitors", Bioinformation, vol. 4, (2010), pp. 4: 357- 365.

[26] P. Zakeri- Milani, H. Tajerzadeh, Z. Islambolchilar, S. Barzegar and H. Valizadeh, "The relation between molecular roperties of drugs and their transport across the intestinal membrane", DARU, vol. 14, (2006), pp. 164- 171 